\title{
Com a Palavra os Nobres Deputados: Ênfase Temática dos Discursos dos Parlamentares Brasileiros
}

\author{
Davi Moreira
}

Professor visitante do Departamento de Ciência Política da Universidade Federal de Pernambuco (UFPE). Recife, Pernambuco. Brasil.

E-mail: davi.moreira@gmail.com, https:/ /orcid.org/0000-0003-3966-1730

\section{INTRODUÇÃO}

\begin{abstract}
Com uso instrumental e estratégico conhecido há milênios (Aristóteles, 2012, século IV a.c.), a comunicação é elemento fundamental da política, desempenhando papel central nas relações de poder da sociedade e de representação nos regimes democráticos modernos (Foucault, 1996; Manin, 1997). Através dela os representantes políticos apresentam e debatem projetos de lei, participam de eventos, palestras e seminários, publicam e postam mensagens em redes sociais, gravam programas de TV, vídeos na internet e, ainda, prestam contas de suas atividades. Por essa razão, tal atividade possui lugar especial nas pesquisas em ciência política.
\end{abstract}

A despeito de sua importância, a escassez de tempo, de recursos e a vulnerabilidade à qual o rigor do pesquisador está sujeito ao analisar de forma manual o conteúdo de grandes bases de texto (corpus) faz com que boa parte das pesquisas com esse propósito se limite à análise de pequenos acervos. Por essa razão, a maior parte dos trabalhos nessa área realiza recortes profundos sobre a atividade política, produzindo conhecimento esparso e inviabilizando conclusões gerais a respeito de atividade tão importante.

Revertendo esse quadro limitado, o avanço tecnológico e científico permitiu que técnicas automatizadas de análise do conteúdo fossem desenvolvidas e aplicadas de forma simples a grandes volumes de documentos através de modelos probabilísticos (Grimmer, 2015; Monroe, 2013; Monroe e Schrodt, 2008; Roberts, 2016). Acompanhando esse desenvolvimento recente, este artigo reconhece o discurso como um dos meios

DADOS, Rio de Janeiro, vol.63(1): e20180176, 2020.

http://dx.doi.org/10.1590/001152582020204 
pelos quais a política se materializa e se dedica à análise do conteúdo de mais de 127 mil pronunciamentos realizados por mais de 2 mil oradores diferentes ao longo de mais de 15 anos de atividade parlamentar (1999-2014). Considerando que o atual desenvolvimento metodológico do campo de estudos legislativos no Brasil se faz profícuo para esse avanço, este artigo pretende abrir novos rumos para as pesquisas que se dedicam à análise de conteúdo e à atividade parlamentar.

Focada na análise do processo decisório, o conhecimento produzido sobre a atividade parlamentar no caso brasileiro apresenta que este é guiado pela relação governo-oposição, seguindo os pressupostos da tese do presidencialismo de coalizão (Abranches, 1988; Arretche, 2007; Figueiredo e Limongi, 1999, 2002; Limongi e Figueiredo, 1998; Zucco, 2009). Apesar da robustez que as análises a respeito do processo decisório ganharam na agenda de estudos legislativos brasileira, pouco se sabe sobre a comunicação parlamentar realizada através de momentos institucionais regimentalmente previstos.

De forma mais frequente do que a elaboração e a aprovação de leis, por exemplo, cotidianamente deputados federais acessam a tribuna da Câmara dos Deputados (CD) para proferir explanações a respeito de sua atividade, sua posição em relação a algum tema específico, homenagear alguma personalidade ou ente querido, responder a indagações e dessa maneira alcançar colegas, eleitores e correligionários ${ }^{1}$. Mesmo com tamanha frequência, a ciência política brasileira pouco conhece sobre a atividade de comunicação parlamentar no âmbito do Congresso Nacional. Não se sabe o volume de falas, o padrão de uso dos momentos institucionais previstos para comunicação e muito menos o conteúdo expresso nesses discursos. Dado esse fato, menor ainda é o conhecimento dos padrões que regem essa atividade parlamentar e os efeitos das principais variáveis que orientam esse comportamento congressista ${ }^{2}$.

Valendo-se da rica literatura que analisa a votação nominal na CD (Limongi e Figueiredo, 1998, 2005; Pereira e Mueller, 2000, 2002, 2003; Zucco, 2009; Zucco Jr. e Lauderdale, 2011) e a produção do conteúdo legislativo aprovado (Freitas, 2010; Freitas, A.,2013; Moreira, 2011; Ricci, 2003, 2006) o artigo responde a seguinte questão: as agendas proferidas pelos parlamentares em discursos no plenário da Câmara dos Deputados são governadas pela relação governo/oposição, assim como constatado sobre sua atuação no processo decisório? 
Os resultados aqui apresentados são o princípio de uma profícua agenda de pesquisa no campo dos estudos legislativos e comportamento político no Brasil que têm em como principal contribuição a análise do texto como dado (text as data). Amparados pelas regras que organizam os trabalhos na $\mathrm{CD}$, porém distantes dos regulamentos que regem os processos decisórios, a primeira seção do artigo faz uma apresentação geral dos momentos institucionais de fala previstos regimentalmente na CD, justifica a escolha do Pequeno Expediente como foco dessa pesquisa e analisa brevemente a frequência de uso desse momento institucional pelos deputados federais ao longo das legislaturas 51 a 54 .

Após destacar que a comunicação se constitui como dimensão importante da atividade parlamentar no âmbito da $C D$, se faz conveniente analisar quais os principais temas abordados pelos deputados federais brasileiros ao discursarem. Para tanto, apresenta na seção seguinte $\mathrm{o} e x-$ pressed agenda model, metodologia empregada para classificação substantiva dos discursos e captação da ênfase temática de cada parlamentar.

A terceira seção apresenta os resultados obtidos com a aplicação do expressed agenda model nos discursos proferidos no Pequeno Expediente das legislaturas 51 a 54. Ademais, como em qualquer outro procedimento de classificação de conteúdo, são apresentadas distintas formas de validação adotadas para averiguar se os resultados são substantivamente relevantes.

Com o objetivo de elucidar padrões gerais desta atividade parlamentar ainda pouco explorada na ciência política nacional, na quarta seção investiga-se como os deputados federais brasileiros se diferenciam diante de duas áreas bastante recorrentes no debate político: a agenda social e a agenda econômica. Por fim, são apresentadas as considerações finais.

\section{A COMUNICAÇÃO PARLAMENTAR NA CÂMARA DOS DEPUTADOS}

A atividade parlamentar no âmbito da $C D$ vai além da votação e apresentação de projetos de lei (Moreira, 2019). Um deputado federal possui tempo, espaço, recursos e infraestrutura dedicados à comunicação política que não se restringem aos projetos em pauta, garantindo à atividade parlamentar a oportunidade de não se submeter à agenda legislativa. É justamente pelo fato de a fala parlamentar ter a 
possibilidade de se concretizar em ambiente de relativa independência em relação ao processo decisório que este artigo busca investigar como se distinguem os parlamentares em relação à ênfase temática dos discursos proferidos em plenário e avançar na análise de outras dimensões da atividade parlamentar.

As sessões ordinárias da $C D$, com duração de cinco horas (art. 66, Regimento Interno da Câmara dos Deputados - RICD), possuem quatro fases, nessa ordem: Pequeno Expediente, Grande Expediente, Ordem do Dia e Comunicações Parlamentares ${ }^{3}$. No Pequeno Expediente (primeira fase), seus sessenta minutos ${ }^{4}$ de duração regimentalmente previstos são dedicados à leitura da matéria do expediente ${ }^{5} \mathrm{e}$ aos oradores inscritos.

Segundo o RICD, abertos os trabalhos de uma sessão legislativa, no Pequeno Expediente os deputados federais podem falar por até cinco minutos num intervalo de sessenta minutos em cada sessão legislativa. A inscrição dos oradores é feita na Mesa, em caráter pessoal e intransferível, em livro próprio, das $8 \mathrm{~h}$ às $13 \mathrm{~h} 30 \mathrm{~m}$, diariamente, assegurada a preferência aos que não hajam falado nas cinco sessões anteriores. As inscrições que não puderem ser atendidas em virtude do levantamento ou não realização da sessão serão transferidas para a sessão ordinária seguinte. Com tais características, o Pequeno Expediente é o momento regimental que permite maior acesso e liberdade por parte do deputado para expor suas ideias e proferir seus discursos.

Se com base nas regras que regem os momentos de fala livre dos parlamentares identifica-se que o Pequeno Expediente possui vantagens comparativas, resta saber se essa vantagem se configura na prática. A seguir, são apresentadas informações referentes ao uso do Pequeno Expediente ao longo das legislaturas analisadas.

\section{A fala na Câmara dos Deputados e o uso do Pequeno Expediente}

De acordo com os dados disponibilizados pela CD, 270.014 pronunciamentos foram realizados pelos deputados federais entre 1999 e 2014, uma média de quase $17 \mathrm{mil} \mathrm{ao} \mathrm{ano}{ }^{6}$. 
Figura 1

Proporção de uso dos momentos institucionais de pronunciamento pelos deputados federais

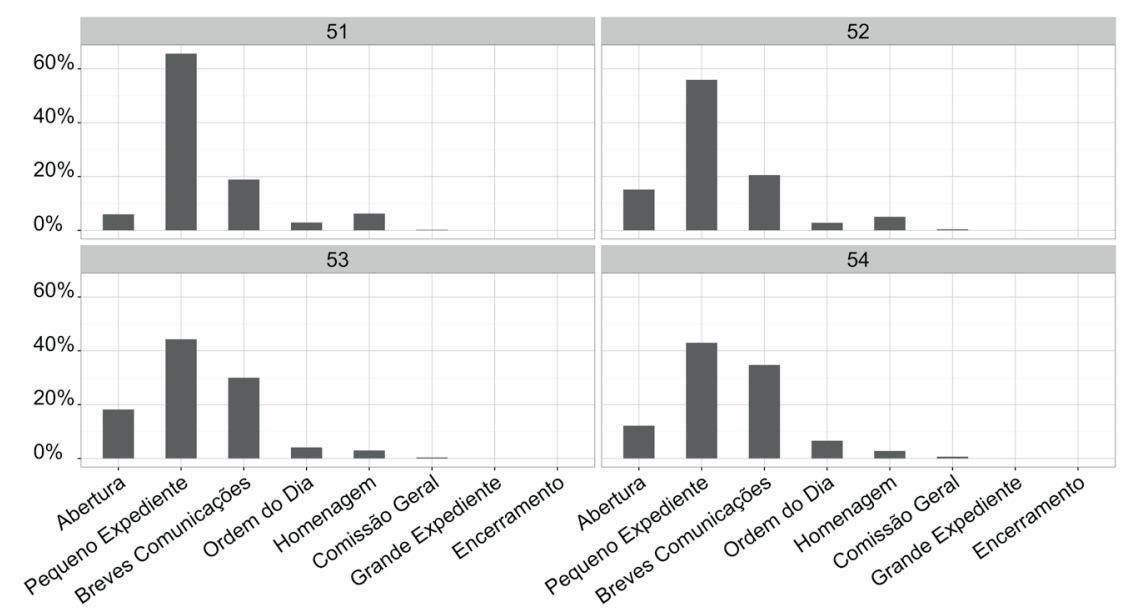

Fonte: elaboração própria com dados da Câmara do Deputados.

Se a quantidade de pronunciamentos realizados ao longo das legislaturas 51 a 54 evidencia a importância do uso da fala na atividade parlamentar no âmbito da CD, a Figura 1 deixa clara a relevância do Pequeno Expediente em relação a todos os momentos institucionais de pronunciamento parlamentar. É em virtude de tamanha relevância que os discursos proferidos nesse momento institucional foram escolhidos como objeto deste estudo.

Um total de 2.579 deputados federais diferentes compuseram as legislaturas analisadas ${ }^{7}$. Desses, $2.262(87,7 \%)$ realizaram ao menos um discurso no Pequeno Expediente ${ }^{8}$.

Há, em média, 58,7 discursos proferidos no Pequeno Expediente por deputado federal que proferiu algum discurso 9 . A Tabela 1 apresenta os dados descritivos da quantidade de discursos proferidos no Pequeno Expediente por deputados federais em cada legislatura. 
Tabela 1

Dados descritivos da quantidade de discursos proferidos no Pequeno Expediente por deputados federais em cada legislatura.

\begin{tabular}{lcccc}
\hline Legislatura & 51 & 52 & 53 & 54 \\
\hline Mín. & 0 & 0 & 0 & 0 \\
1Q. & 2 & 9 & 7 & 5 \\
Mediana & 10 & 34 & 27 & 20 \\
Média & 30,9 & 66,7 & 57,6 & 52,8 \\
3Q. & 41 & 87,5 & 70,5 & 55 \\
Máx. & 785 & 1.111 & 1.072 & 1.235 \\
\hline \# zeros & 118 & 54 & 63 & 80 \\
\# Deputados & 526 & 572 & 573 & 591 \\
\# Discursos & 19.883 & 41.756 & 36.613 & 35.398 \\
\hline
\end{tabular}

Fonte: elaboração própria com dados da Câmara do Deputados.

Constata-se, portanto, que o uso dos recursos de comunicação disponíveis no Pequeno Expediente varia de acordo com cada parlamentar, indicando que a propensão ao discurso pode advir de características pessoais de cada um. Foco de trabalho já em desenvolvimento, esse aspecto não será aqui analisado com o objetivo de se dedicar atenção ao conteúdo pronunciado pelos deputados federais nessa oportunidade institucional de comunicação.

Com o uso de técnicas de programação e modelos probabilísticos, a partir da próxima seção o artigo se dedica a avaliar o conteúdo pronunciado pelos deputados federais brasileiros nos pronunciamentos realizados no Pequeno Expediente. Não é propósito do artigo explicar em termos causais o comportamento dos parlamentares brasileiros, mas sim compreender padrões gerais de uma complexa dimensão da atividade legislativa ainda pouco explorada na ciência política nacional (Gelman, 2003, 2004, 2007, 2011). 


\section{METODOLOGIA}

O avanço tecnológico e científico permitiu que técnicas automatizadas de análise do conteúdo fossem desenvolvidas e aplicadas de forma simples a grandes volumes de documentos através de modelos probabilísticos.

Dada a complexidade da comunicação e da linguagem, transformar palavras em números não substitui a leitura cuidadosa e atenta de documentos, mas permite a análise sistemática de grandes bases de texto sem a necessidade de mão de obra em larga escala e de um enorme montante de recursos financeiros para financiamento de pesquisas, amplificando o potencial científico dos trabalhos acadêmicos.

Entre os diferentes modelos disponíveis, para a possibilidade de classificação automática do conteúdo dos discursos proferidos no Pequeno Expediente, destaca-se o expressed agenda model (Grimmer, 2010), técnica de classificação baseada no probabilistic topic modeling (Blei, 2012) que utiliza aprendizagem computacional não supervisionada para a identificação de tópicos em uma coleção de documentos. É com o uso desse método que é analisada a ênfase temática dos parlamentares brasileiros no Pequeno Expediente.

O expressed agenda model é um modelo de clusterização de documentos desenvolvido pelo cientista político Justin Grimmer (2010). O objetivo principal desse modelo é verificar como a ênfase em diferentes temas varia entre os documentos produzidos por distintos autores. Com esse propósito, o modelo opera em dois níveis: o nível dos autores e o nível dos documentos (Figura 2).

Figura 2

Estrutura hierárquica do expressed agenda model

$\begin{array}{ccccc}\text { Deputado }_{1} & \text { Deputado }_{2} & \text { Deputado }_{3} & \ldots & \text { Deputado }_{n} \\ \downarrow & \downarrow & \downarrow & & \downarrow \\ \text { Discursos }_{\text {Deputado }_{1}} & \text { Discursos }_{\text {Deputado }_{2}} & \text { Discursos }_{\text {Deputado }_{3}} & \ldots & \text { Discursos }_{\text {Deputado }_{n}} \\ \text { Fonte: elaboração própria com dados da Câmara do Deputados. } & & \end{array}$


Considerando os dois níveis de informação e o caso deste artigo, de modo geral, o modelo agrupa as palavras contidas nos discursos de acordo com sua frequência relativa em cada um. Em seguida são gerados grandes grupos de palavras que dão origem aos temas e, posteriormente, se obtém a ênfase dada por cada deputado aos diferentes temas proferidos.

A seguir estão apresentados os detalhes do expressed agenda model, sua aplicabilidade para o caso brasileiro e procedimentos utilizados para obtenção e limpeza dos dados utilizados no modelo.

\section{0 expressed agenda mode ${ }^{10}$}

A escolha do expressed agenda model foi feita em função de dois aspectos: um relacionado à compatibilidade do modelo desenvolvido (Grimmer, 2010) com as características institucionais do Pequeno Expediente e outro em função das características deste espaço institucional comparadas aos demais momentos previstos para a fala dos parlamentares conforme apresentado na primeira seção deste artigo.

Em relação ao primeiro aspecto, o expressed agenda model supõe que cada documento que será analisado se dedique a somente um tópico $^{11}$ (Grimmer, 2010: 8). Segundo o RICD, abertos os trabalhos de uma sessão legislativa, no Pequeno Expediente os deputados federais podem falar por até cinco minutos. Em contraposição ao Grande Expediente, momento no qual cada parlamentar pode discursar por até 25 minutos, acredita-se que nos cinco minutos disponíveis para o pronunciamento durante o Pequeno Expediente, cada parlamentar utilize este tempo para acessar somente um tópico com o objetivo de maximizar o foco temático de sua fala.

Com os discursos agrupados segundo cada parlamentar (autor) os dados ficam naturalmente organizados de forma hierárquica. Como na Figura 2, no topo da hierarquia temos $n$ autores, indexados por $i=1, \ldots, n$. Cada autor pode decidir quanta atenção dedicar a um número $k,(k=1, \ldots, k)$, de tópicos. $\mathrm{O}$ vetor descrevendo a atenção que cada autor dedica a cada tópico é sua "agenda expressa" ou sua ênfase temática e probabilisticamente determina a frequência com que cada tópico aparece nos discursos de cada parlamentar. 
No piso da hierarquia, temos a coleção de discursos de cada autor, denotados por $j,\left(j=1, \ldots, D_{i}\right)$, em que um discurso do autor $i$ é representado pelo vetor $w \times 1$ e denotado $y_{i j}$. Desse modo, o elemento $y_{i j z}$, de $y_{i j^{\prime}}$ mede o número de vezes que a zésima palavra ocorre no jésimo discurso do iésimo autor.

Para conectar os tópicos dos autores com o conteúdo de seus discursos, supõe-se que cada discurso tenha apenas um tópico. O tópico de cada discurso é um sorteio aleatório, com a probabilidade de um tópico específico ocorrer segundo a atenção que o autor $i$ dedica a esse tópico. Condicional a esse tópico amostrado, o conteúdo de um discurso advém de uma distribuição específica a cada tópico.

Formalmente, o expressed agenda model é um modelo hierárquico no qual a ênfase temática pode variar entre os deputados, mas os componentes do modelo (tópicos) estão fixos entre os autores para garantir que as agendas sejam comparáveis entre eles. Para completar, supõe-se que haja um total de $D=\sum_{i=1}^{n} D_{\mathrm{i}}$ discursos em uma $D \times w$ matriz $Y$.

\section{Obtenção, pré-processamento e organização dos dados}

Praticamente tudo que é dito nos momentos institucionais previstos pelo RICD é gravado, arquivado e disponibilizado ao cidadão na internet $^{12}$. Hoje é possível de forma rápida e automatizada obter as informações e os pronunciamentos dos deputados federais.

Obtidos os dados ${ }^{13}$, para o uso do expressed agenda model dois desafios são colocados no caso brasileiro: sua adaptação ao sistema político e sua adequação à língua portuguesa.

O primeiro desafio está vinculado ao objeto de análise deste artigo. No caso de um discurso, a fala de um parlamentar pode se debruçar sobre uma série de temas, mesmo que um seja mais relevante do que o outro. Esse aspecto faz com que o Pequeno Expediente, além das vantagens regimentais já apresentadas, tenha vantagens analíticas em relação aos demais momentos institucionais de fala, pois se trata de apenas cinco minutos de discurso por parlamentar que se acredita serem otimizados com o foco sobre apenas um tema. 
O segundo desafio está relacionado à etapa de tratamento dos dados. Com o objetivo de se obter uma "sacola de palavras" (bag of words) de cada discurso, cada pronunciamento passa por uma "limpeza" que consiste em cinco passos: i) todas as palavras são colocadas em caixa baixa; ii) são retirados todos os números dos documentos; iii) toda pontuação é removida, inclusive acentos; iv) são removidas as stop words (artigos, preposições etc.); v) e, por fim, para garantir que palavras que variam apenas na flexão, número ou conjugação sejam consideradas iguais, reduzindo o número de dimensões contido no corpus, através da adaptação do algoritmo de Porter (1980) para o Português já desenvolvida por diferentes projetos (Snowball e NILC-USP), são obtidos os stems das palavras restantes ${ }^{14}$.

Ao final, utilizando somente as sacolas de palavras de autores que possuem mais de um documento (discurso, no caso deste artigo), é construída uma Document Term Matrix (DTM), $d$ x w, cujas linhas representam cada discurso e as colunas representam cada stem presente no corpus (coleção de documentos). É essa matriz que será utilizada na estimação dos tópicos das falas dos deputados ${ }^{15}$.

Ademais, Grimmer (2010) retira do corpus todas as palavras que estão presentes em $0,5 \%$ dos documentos e também retira dos documentos de cada autor as palavras que aparecem em mais de $90 \%$ dos documentos de cada $\mathrm{um}^{16}$.

Além da DTM acima citada, o expressed agenda model recebe como argumento uma matriz de autores, $n \times 2$, cujas linhas representam cada autor, a primeira coluna representa a linha do primeiro discurso do autor na DTM e a segunda representa a linha do último discurso deste autor na DTM. Convém ressaltar novamente mais uma exigência do modelo, pois serão aceitos apenas os discursos de autores que fizeram mais de um pronunciamento.

Conforme apresenta a Tabela 2, adotando a estratégia de tratamento de dados apresentada e procedimentos que garantissem a seleção de registros com conteúdo realmente dedicado ao Pequeno Expediente, há uma queda no número total de discursos em cada legislatura e, consequentemente, no número de oradores que serão analisados. Contudo, a principal informação que salta aos olhos é a diferença 
entre a contagem de palavras únicas presentes em toda a coleção de discursos e o resultado final apresentando o número de stems únicos que serão utilizados para classificação temática dos discursos.

Tabela 2

Resultado do pré-processamento aplicado à coleção de discursos de cada legislatura.

\begin{tabular}{lrrrr}
\hline & 51 & 52 & 53 & 54 \\
\hline \# inicial de discursos & 19.883 & 41.756 & 36.613 & 35.398 \\
\# final de discursos & 19.064 & 39.702 & 35.075 & 33.941 \\
\# inicial de oradores & 526 & 572 & 573 & 591 \\
\# final de oradores & 491 & 548 & 543 & 552 \\
\# inicial de palavras únicas na coleção & 119.480 & 160.674 & 152.791 & 153.111 \\
\# Stems únicos & 4.104 & 3.989 & 3.757 & 3.906 \\
\hline
\end{tabular}

Fonte: elaboração própria com dados da Câmara do Deputados.

Apesar de serem coisas diferentes (palavras e stems), essa comparação justamente destaca como a eficiência de modelos estatísticos automatizados para análise de conteúdo necessita de uma redução brusca de informação. Pode-se concluir que muita informação presente nos discursos publicados não será utilizada para sua classificação temática. Entretanto, como será apresentado na terceira seção deste artigo, o trade-off entre utilizar modelos estatísticos automatizados para análise de conteúdo e a mão de obra humana para classificação manual de tamanho volume de dados favorece o uso da primeira abordagem. Para o momento, apenas com os stems é possível ter uma ideia substantiva da matéria-prima obtida após o pré-processamento dos dados, como pode ser visto nas Figuras 3 e 4 . 
Figura 3

Nuvem de stems comuns em todas as legislaturas

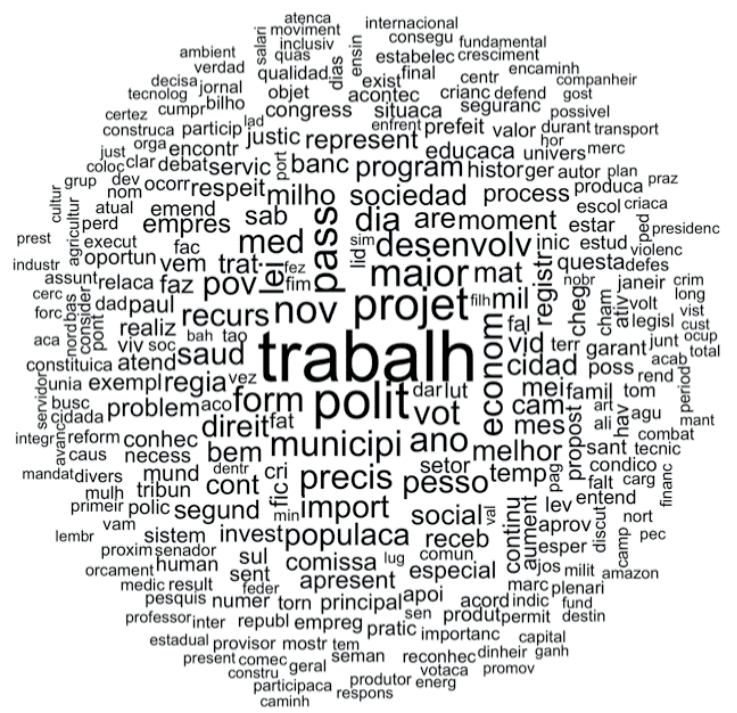

Fonte: elaboração própria com dados da Câmara do Deputados.

Figura 4

Comparação da nuvem de stems mais utilizados em cada legislatura quando comparada às demais

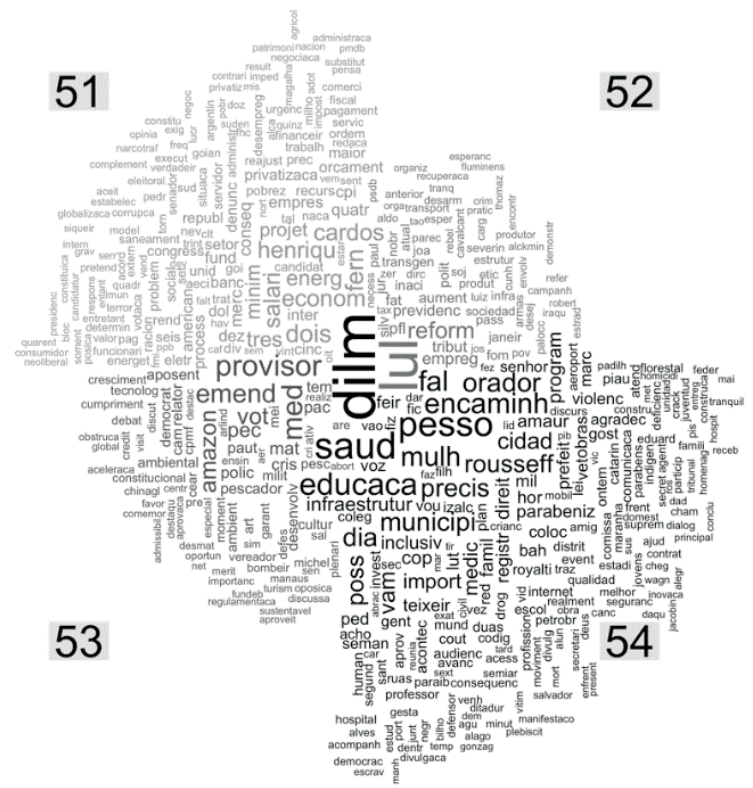

Fonte: elaboração própria com dados da Câmara do Deputados. 
A Figura 3 apresenta os principais stems comuns em todas as legislaturas. $\mathrm{O}$ tamanho de cada um reproduz visualmente sua frequência, sendo notável o destaque dos stems trabalh, polit, projet e econom.

Por sua vez, a Figura 4 também reproduz visualmente a frequência de uso dos stems, mas, nesse caso, compara os stems das quatro legislaturas analisadas e apresenta, para cada legislatura, aquela que foi mais utilizada em relação às demais. $\mathrm{O}$ stem lul, por exemplo, por mais que tenha sido utilizado em outras legislaturas, teve seu maior uso na legislatura 52. De forma geral, a visualização da Figura 4 sugere um indicativo de temas que os deputados federais mais se dedicaram em cada uma das legislaturas. Na legislatura 54, é possível identificar os stems dilm, pesso, mulh, saud, educaca como mais utilizados quando comparados às demais legislaturas. Na legislatura 53, é possível identificar os stems med, provisor, emend, vot, amazon como mais utilizados. Na legislatura 52 se destacam os stems lul, reform, empreg, tribut, previdenc. Por fim, na legislatura 51, ganham destaque os stems econom, energ, salari, henriqu, cardos.

Tem-se, portanto, uma primeira imagem da matéria-prima obtida a partir dos procedimentos de pré-processamento apresentados. É ela que será utilizada na terceira seção para a identificação da agenda expressa pelos deputados federais no Pequeno Expediente. Porém, antes de prosseguir com a estimação dos tópicos, resta ainda apresentar os últimos desafios a serem superados para a implementação do expressed agenda model.

\section{Quantidade de temas e procedimentos de validação}

Outro desafio imposto pelo modelo é a definição do número de tópicos $k$ presente em cada corpus, ou seja, a quantidade de temas abordados em cada uma das legislaturas analisadas ${ }^{17}$. Com a premissa de que cada discurso trata de um único tema, no limite, $k=n$, onde $n$ é o número de discursos proferidos no Pequeno Expediente em cada legislatura. No entanto, com base em Grimmer (2010), para a definição do número $k$ de tópicos, foram utilizadas duas estratégias: i) o uso de um modelo não paramétrico para clusterização de texto baseado no Dirichlet process prior (Blei e Lafferty, 2006; Grimmer, 2010); e ii) a estimação de diferentes modelos para cada legislatura. 
Adotando o mesmo critério para cada legislatura, o modelo não paramétrico resultou num diferente número de tópicos presente no corpus de cada uma delas ${ }^{18}$. No entanto, estes resultados não foram considerados de forma definitiva e a estipulação da quantidade $k$ de tópicos contou com uma avaliação qualitativa do resultado de diferentes modelos para cada legislatura. A avaliação qualitativa permite que o valor $k$ seja definido pela coesão substantiva identificada pelo analista através da análise dos stems mais associados a cada tópico em diferentes modelos.

Tabela 3

Dados descritivos dos discursos proferidos no Pequeno Expediente por deputados federais em cada legislatura que serão utilizados no expressed agenda model.

\begin{tabular}{lcccc}
\hline & 51 & 52 & 53 & 54 \\
\hline Mín. & 2 & 2 & 2 & 2 \\
1Q. & 7 & 15 & 12.5 & 10 \\
Mediana & 20 & 38.5 & 33 & 28 \\
Média & 38.83 & 72.45 & 64.59 & 61.49 \\
3Q. & 48.50 & 94 & 76 & 65.25 \\
Máx. & 783 & 1.081 & 983 & 1.190 \\
\hline \# Deputados & 491 & 548 & 543 & 552 \\
\# Discursos & 19.064 & 39.702 & 35.075 & 33.941 \\
\# Stems únicos & 4.104 & 3.989 & 3.757 & 3.906 \\
\# Tópicos & 27 & 31 & 31 & 39 \\
\hline
\end{tabular}

Fonte: elaboração própria com dados da Câmara do Deputados.

Portanto, para cada legislatura foram estimados e analisados os resultados de modelos que variaram de cinco a oitenta tópicos. Por um lado, comparados entre si, quanto menor o número de tópicos de um modelo, maior é a diversidade de discursos classificados em cada um, resultando em categorias muito genéricas. Por outro lado, quanto maior o número de tópicos do modelo, maior é a quantidade de tópicos tratando sobre o mesmo tema. Por essa razão, com o auxílio da evidência estatística do modelo não paramétrico, foi possível analisar de forma qualitativa os resultados dos 75 modelos estimados de cada legislatura para a obtenção de um resultado final ${ }^{19}$, conforme $^{2}$ apresenta a Tabela 3. 
Além dos resultados obtidos com a aplicação do modelo estatístico, como em qualquer outro procedimento de classificação de conteúdo, são apresentadas distintas formas de validação adotadas para averiguar se os resultados são substantivamente relevantes. Mais do que averiguar se o modelo capta a realidade, importa responder se os resultados são teoricamente úteis. Consolidadas na literatura da Ciência Política e da Ciência da Computação, os tópicos são validados através de quatro procedimentos: i) dado que a matéria-prima para a análise dos tópicos são os stems das palavras contidas nos discursos, verifica-se quais os dez stems mais associados a cada um através do cálculo de sua Informação Mútua (Grimmer, 2010, 2013)20; ii) são lidos ao menos dez discursos aleatoriamente selecionados para rotulação de cada tópico; iii) sendo cada discurso pertencente a um tópico, é analisada sua relevância ao longo de cada legislatura através da frequência dos tópicos no tempo; iv) é qualitativamente analisada a dedicação de parlamentares selecionados a tópicos específicos, de modo que seja possível identificar se há coerência entre a classificação temática dos discursos e perfis parlamentares amplamente conhecidos e difundidos na sociedade e na ciência política brasileira.

A seguir, portanto, são apresentados os tópicos obtidos para cada legislatura analisada.

\section{COM A PALAVRA OS NOBRES DEPUTADOS}

\section{Temas abordados pelos deputados federais}

Analisando separadamente cada legislatura, foram estimados os tópicos presentes nos discursos dos deputados federais que fizeram mais de um pronunciamento. As Tabelas 4, 5, 6 e 7, respectivamente referentes às legislaturas 51, 52, 53 e 54, apresentam os tópicos estimados.

Na primeira coluna é apresentado o rótulo dado a cada tópico após a leitura de uma amostra de ao menos dez discursos aleatoriamente selecionados de cada um deles. Nela também se encontram, classificados em negrito, tópicos próprios da Área Econômica e, em itálico e sublinhados, tópicos próprios da Área Social ${ }^{21}$. É através desse rótulo que serão feitas as referências aos tópicos na continuidade desse artigo e, para facilitar a compreensão dos temas tratados pelos deputados federais entre as diferentes legislaturas, tomou-se o cuidado de se utilizar rótulos semelhantes entre as legislaturas quando, após análise, isto se fez conveniente. 
Na segunda coluna, é possível verificar até o quinto stem com maior Informação Mútua em cada tópico.

Na terceira, é apresentado o percentual de documentos do corpus classificado em cada um dos tópicos para cada legislatura.

Tabela 4

Temas dos discursos proferidos na legislatura 51.

\begin{tabular}{|c|c|c|}
\hline Rótulo & Stems & $\%$ \\
\hline Questões legislativas & mat, mes, plenari, lid, comissa & 8,4 \\
\hline Projetos de lei & projet, lei, comissa, aprov, apresent & 6,2 \\
\hline $\begin{array}{l}\text { Datas comemorativas e } \\
\text { homenagens }\end{array}$ & cidad, jornal, trabalh, dia, histor & 6,2 \\
\hline Sistema político & polit, pov, candidat, trabalh, eleitoral & 6,1 \\
\hline Votação & vot, mat, votaca, projet, lid & 5,9 \\
\hline Trabalho & trabalh, direit, projet, empreg, lei & 5,7 \\
\hline Questões municipais & municipi, prefeit, cidad, populaca, recurs & 4,9 \\
\hline Amazônia e meio ambiente & regia, desenvolv, amazon, agu, projet & 4,4 \\
\hline Direitos humanos e minorias & direit, human, sociedad, pesso, negr & 4,1 \\
\hline Economia & econom, polit, desenvolv, ano, setor & 4,0 \\
\hline Corrupção & cpi, denunc, corrupca, senador, fat & 3,8 \\
\hline Agropecuária & produtor, produca, agricultur, produt, milho & 3,4 \\
\hline$\underline{\text { Educação }}$ & educaca, ensin, escol, univers, professor & 3,3 \\
\hline Medida Provisória & med, provisor, vot, mat, lei & 3,2 \\
\hline Saúde & saud, medic, atend, recurs, trabalh & 3,1 \\
\hline Segurança & polic, seguranc, milit, violenc, crim & 3,0 \\
\hline Empresas & empres, petrobr, servic, trabalh, maior & 2,9 \\
\hline Emenda parlamentar & emend, fund, recurs, orcament, projet & 2,8 \\
\hline Energia & energ, eletr, setor, cris, invest & 2,8 \\
\hline Transporte & transport, rodov, estrad, recurs, trech & 2,4 \\
\hline ALCA e Terrorismo & american, unid, mund, econom, nort & 2,3 \\
\hline Sistema Financeiro & banc, financeir, credit, central, econom & 2,1 \\
\hline$\underline{\text { Gênero e pobreza }}$ & mulh, crianc, program, trabalh, famil & 2,1 \\
\hline$\underline{\text { Servidores públicos }}$ & servidor, salari, trabalh, servic, reajust & 2,0 \\
\hline Salário mínimo & salari, minim, trabalh, aposent, reajust & 1,6 \\
\hline Questão indigena e fundiária & terr, trabalh, agrar, reform, assent & 1,5 \\
\hline Sistema Tributário & impost, tribut, rend, aument, reform & 1,4 \\
\hline
\end{tabular}

Obs.: Temas próprios da Área Econômica estão em negrito e temas próprios da Área Social estão sublinhados e em itálico.

Fonte: elaboração própria com dados da Câmara do Deputados. 
Tabela 5

Temas dos discursos proferidos na legislatura 52

\begin{tabular}{|c|c|c|}
\hline Rótulo & Stems & $\%$ \\
\hline Votação & vot, mat, lid, plenari, votaca & 10,3 \\
\hline $\begin{array}{l}\text { Homenagens e datas } \\
\text { comemorativas }\end{array}$ & pov, vid, dia, trabalh, jornal & 6,8 \\
\hline Projetos de lei & projet, lei, aprov, vot, mat & 5,8 \\
\hline Medida Provisória & med, provisor, emend, vot, lei & 5,2 \\
\hline Sistema político & polit, trabalh, pov, reform, vot & 4,7 \\
\hline Trabalho & trabalh, empreg, direit, pass, dia & 4,7 \\
\hline Lula e PT & lul, pov, polit, trabalh, republ & 4,6 \\
\hline Desenvolvimento & desenvolv, econom, nov, projet, trabalh & 4,4 \\
\hline Educação & educaca, ensin, univers, escol, professor & 3,4 \\
\hline Agropecuária & produtor, produt, agricultur, produca, setor & 3,4 \\
\hline Seguranca Pública & polic, seguranc, crim, milit, trabalh & 3,3 \\
\hline Questões municipais & municipi, prefeit, populaca, regia, recurs & 3,2 \\
\hline Saúde & saud, medic, atend, hospital, populaca & 3,1 \\
\hline Economia & econom, polit, jur, cresciment, ano & 3,0 \\
\hline Justica e Direitos Humanos & direit, justic, human, pesso, sociedad & 2,9 \\
\hline Questões regionais & cidad, municipi, regia, trabalh, populaca & 2,9 \\
\hline Criança e Adolescente & crianc, pesso, violenc, sociedad, adolescent & 2,8 \\
\hline Empresas & empres, servic, trabalh, setor, empreg & 2,7 \\
\hline Prefeitos e vereadores & prefeit, municipi, cidad, vereador, polit & 2,6 \\
\hline Transporte & transport, rodov, estrad, trech, recurs & 2,3 \\
\hline Servidor público e previdência & servidor, previdenc, trabalh, reform, social & 2,1 \\
\hline Programas federais & program, famil, fom, social, milho & 2,0 \\
\hline Sistema financeiro & banc, econom, financeir, trabalh, credit & 1,9 \\
\hline Recursos e investimentos & orcament, recurs, milho, ano, emend & 1,8 \\
\hline Amazônia e meio ambiente & amazon, regia, desenvolv, are, florest & 1,8 \\
\hline Salário minimo & salari, minim, trabalh, aument, valor & 1,7 \\
\hline Sistema tributário & tribut, impost, reform, aument, carg & 1,6 \\
\hline Gênero & mulh, trabalh, violenc, direit, dia & 1,4 \\
\hline Questão fundiária & terr, trabalh, agrar, reform, assent & 1,3 \\
\hline Questão hídrica & agu, francisc, recurs, projet, transposica & 1,2 \\
\hline Questão indígena & indigen, indi, terr, are, pov & 0,9 \\
\hline
\end{tabular}

Obs.: Temas próprios da Área Econômica estão em negrito e temas próprios da Área Social estão sublinhados e em itálico.

Fonte: elaboração própria com dados da Câmara do Deputados. 
Tabela 6

Temas dos discursos proferidos na legislatura 53

\begin{tabular}{lll}
\hline Rótulo & Stems & $\%$ \\
\hline Datas comemorativas & dia, jornal, pov, vid, histor & 7,2 \\
Votação & vot, mat, pec, sim, votaca & 6,5 \\
Medida Provisória & med, provisor, vot, mat, paut & 5,8 \\
Traballho & trabalh, empreg, lut, direit, dia & 5,1 \\
Sistema político & polit, lul, reform, pov, trabalh & 5,1 \\
Questões municipais & municipi, prefeit, cidad, recurs, vereador & 4,8 \\
Saudações e homenagens & cidad, prefeit, municipi, trabalh, pov & 4,3 \\
Desenvolvimento regional & regia, desenvolv, invest, sul, nov & 4,2 \\
Educacão & educaca, escol, ensin, professor, univers & 4,0 \\
Projetos de lei & projet, lei, trabalh, aprov, vot & 3,9 \\
Criança e adolescente & crianc, pesso, vid, violenc, crim & 3,9 \\
Saúde & saud, medic, atend, recurs, trabalh & 3,7 \\
Direitos Humanos & direit, justic, human, tribunal, trabalh & 3,7 \\
Agropecuária & produca, produt, agricultur, setor, produtor & 3,4 \\
Liderança parlamentar & lid, acord, vot, votaca, mat & 3,3 \\
Economia & econom, banc, cris, empres, med & 3,3 \\
Segurranca Pública & polic, milit, seguranc, pec, trabalh & 3,3 \\
Questões regimentais & ordem, questa, mat, plenari, mes & 2,9 \\
Emenda parlamentar & emend, vot, relator, apresent, mat & 2,8 \\
Energia e meio ambiente & ambient, energ, mei, ambiental, desenvolv & 2,3 \\
Amazônia & amazon, regia, desenvolv, florest, manaus & 2,3 \\
Programas federais & program, famil, social, desenvolv, trabalh & 2,0 \\
Comissões & comissa, presidenc, especial, cam, constituica & 1,9 \\
Sistema Tributário & tribut, impost, reform, carg, ano & 1,7 \\
Gênero & mulh, trabalh, dia, polit, violenc & 1,7 \\
Questão indígenan e fundiária & terr, indigen, are, indi, pov & 1,5 \\
A pposentadoria e salário mínimo & aposent, salari, minim, trabalh, reajust & 1,5 \\
Questões legislativas & lei, art, med, emend, provisor & 1,1 \\
Petróleo e petrobrás & petrol, petrobr, sal, pre, empres & 1,0 \\
Questão hídrica & agu, francisc, recurs, populaca, projet & 0,9 \\
Pesca & pesc, pescador, trabalh, pesqueir, ativ & 0,8 \\
\hline Obca & & \\
& &
\end{tabular}

Obs.: Temas próprios da Área Econômica estão em negrito e temas próprios da Área Social estão sublinhados e em itálico.

Fonte: elaboração própria com dados da Câmara do Deputados. 
Tabela 7

Temas dos discursos proferidos na legislatura 54

\begin{tabular}{|c|c|c|}
\hline Rótulo & Stems & $\%$ \\
\hline Votação & vot, mat, votaca, sim, projet & 6,1 \\
\hline Datas comemorativas & dia, registr, jos, vid, jornal & 6,0 \\
\hline Trabalho & trabalh, direit, empreg, dia, projet & 4,9 \\
\hline Questões municipais & municipi, prefeit, nov, cidad, recurs & 4,9 \\
\hline Protestos e corrupção & pov, polit, trabalh, precis, dilm & 4,8 \\
\hline Projetos de lei & projet, lei, aprov, trabalh, comissa & 4,5 \\
\hline Questões regionais & cidad, prefeit, municipi, regia, trabalh & 4,0 \\
\hline Educaçã̃o & educaca, escol, professor, ensin, alun & 3,9 \\
\hline Economia & econom, setor, polit, ano, invest & 3,8 \\
\hline Sistema político & polit, reform, vot, eleitoral, campanh & 3,4 \\
\hline Agentes de saúde & saud, agent, atend, recurs, trabalh & 3,4 \\
\hline Medida Provisória & med, provisor, vot, emend, lei & 3,1 \\
\hline Questões regimentais & comissa, lid, titul, art, suplent & 3,1 \\
\hline Segurancạ pública & polic, seguranc, milit, trabalh, crim & 2,9 \\
\hline Empresas & empres, petrobr, milho, trabalh, servic & 2,8 \\
\hline Transporte & transport, rodov, port, sant, sul & 2,6 \\
\hline Agropecuária & agricultur, produtor, produca, produt, famili & 2,6 \\
\hline Sistema de Justiça & justic, tribunal, suprem, defensor, process & 2,5 \\
\hline Recursos e investimentos & milho, mil, invest, municipi, recurs & 2,3 \\
\hline Direitos Humanos & direit, human, comissa, pesso, trabalh & 2,3 \\
\hline Gênero & mulh, violenc, polit, trabalh, dia & 2,2 \\
\hline Pessoa com deficiência & pesso, deficienc, trabalh, direit, vid & 2,1 \\
\hline Crédito financeiro & banc, nord, econom, jur, trabalh & 1,9 \\
\hline Meio ambiente & ambient, mei, ambiental, are, codig & 1,8 \\
\hline Programas federais & program, famil, bols, social, rend & 1,7 \\
\hline Educacão superior & univers, educaca, ensin, curs, estud & 1,7 \\
\hline Questão hídrica & agu, sec, nord, regia, municipi & 1,6 \\
\hline Saúde & saud, hospital, atend, canc, doenc & 1,5 \\
\hline Esporte & cop, mund, esport, futebol, estadi & 1,4 \\
\hline$\underline{\text { Medicina }}$ & medic, saud, trabalh, program, atend & 1,4 \\
\hline Criança e adolescente & crianc, adolescent, violenc, direit, sexual & 1,3 \\
\hline Questão indigena & indigen, terr, indi, pov, direit & 1,2 \\
\hline Servidor Público & servidor, trabalh, servic, pec, direit & 1,2 \\
\hline Energia & energ, eletr, consumidor, tarif, cont & 1,1 \\
\hline Amazônia & amazon, manaus, zon, franc, regia & 1,1 \\
\hline
\end{tabular}


Tabela 7

Temas dos discursos proferidos na legislatura 54. (cont.)

\begin{tabular}{llc}
\hline Rótulo & Stems & $\%$ \\
\hline Drogas e violência & drog, crack, pesso, usuari, saud & 0,8 \\
Idoso e Previdência & idos, aposent, pesso, trabalh, projet & 0,8 \\
Questão racial & negr, dia, polit, populaca, racial & 0,7 \\
Estatuto da juventude & juventud, jovens, polit, direit, trabalh & 0,5 \\
\hline $\begin{array}{l}\text { Obs.: Temas próprios da Área Econômica estão em negrito e temas próprios da Área Social estão } \\
\text { sublinhados e em itálico. } \\
\text { Fonte: elaboração própria com dados da Câmara do Deputados. }\end{array}$
\end{tabular}

Como se pode constatar, os discursos proferidos acessam temas que perduram ao longo das quatro legislaturas e são notoriamente reconhecidos como temas típicos da atividade política contemporânea em regimes democráticos, por exemplo: Educação e Saúde.

Temos, portanto, os principais temas abordados pelos deputados federais ao discursar no Pequeno Expediente ao longo de mais de 15 anos de atividade parlamentar. Convém ressaltar que esse leque aqui exposto não é exaustivo em sua precisão e acurácia, temas relevantes podem estar contidos no interior dos tópicos apresentados. No entanto, foi feita a escolha de limitar a quantidade de tópicos a um número coerente em relação à coesão dos discursos que o compõe. Logo, não se trata de apresentar uma classificação perfeita de tamanho volume de documentos, mas uma que seja válida e contribua para o objetivo do artigo. Sendo assim, a seguir apresentam-se os demais resultados da validação realizada.

\section{Validação}

Já foi possível verificar os resultados de dois dos quatro procedimentos de validação: a leitura atenta de uma amostra aleatória dos discursos presentes em cada tópico para rotulagem adequada e a análise de stems com a maior Informação Mútua em cada um dos tópicos. A seguir, portanto, é avaliada a pertinência temporal dos tópicos e a ênfase temática esperada de alguns parlamentares de perfil amplamente conhecido pela sociedade brasileira e a Ciência Política nacional.

A paixão brasileira pelo futebol somada à escolha do país para sediar a Copa do Mundo FIFA de 2014 e a Copa das Confederações FIFA de 2013 produziu efeitos sobre toda atividade política nacional. Além da 


\section{Davi Moreira}

previsão de investimentos em transporte e infraestrutura, a atividade legislativa federal contou com a necessidade de produzir ordenamento jurídico específico para a realização do evento. Ainda assim, a atividade parlamentar a seu respeito não se restringiu à aprovação de dispositivos legais para sua realização. Conforme a Figura 5 apresenta, em 2012, para aprovação da Lei Geral da Copa (lei ordinária 12.663/12), mas, sobretudo, em 2014, ano do evento, as falas proferidas no Pequeno Expediente trataram de destacar a temática do Esporte, a relevância da Copa do Mundo em território nacional e seus efeitos políticos.

O deputado federal Chico Lopes (Partido Comunista do Brasil - PCdoB, do Ceará), por exemplo, destacou em discurso pronunciado no Pequeno Expediente a sua indignação em relação ao tratamento recebido pela presidenta da República Dilma Rousseff na abertura do evento:

Senhor presidente, senhoras e senhores deputados, senhoras e senhores convidados que nos honram com a sua presença: Fiquei estarrecido e não acreditei no que ouvi e vi. Se fosse um homem que tivesse feito aquilo, diriam que era machismo, mas foram senhoras da alta sociedade, foi um grupo seleto que assistia à solenidade de abertura da Copa do Mundo que se dirigiu à presidente da República com palavras de baixo calão, o que não podemos aceitar. Pedimos ao Ministério da Justiça que procure aprofundar a investigação para saber quem é quem naquela história ${ }^{22}$. (...)

Figura 5

Pronunciamentos classificados na categoria Esporte ao longo da legislatura 54

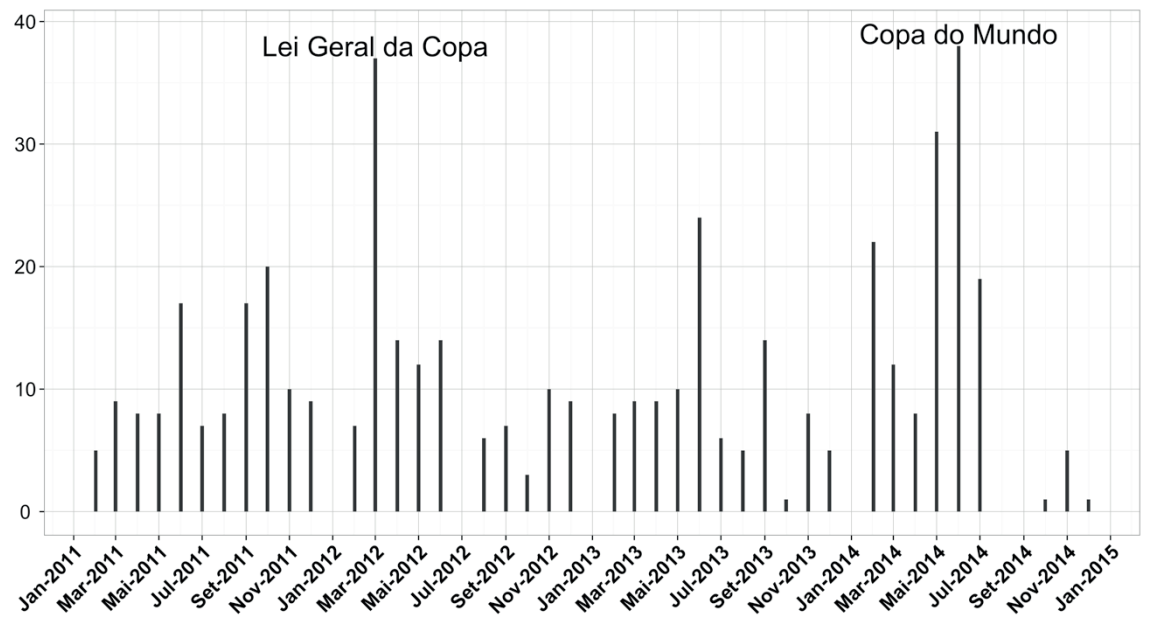

Fonte: elaboração própria com dados da Câmara do Deputados. 
Outros parlamentares, como o deputado federal Giovani Cherini (Partido Democrático Trabalhista - PDT, do Rio Grande do Sul), trataram de avaliar e questionar os efeitos políticos da Copa do Mundo no Brasil:

Senhor presidente, senhoras e senhores parlamentares, eu, como tantos brasileiros, tenho ouvido de Norte a Sul do Brasil aqueles que começam a querer misturar futebol com política. De dois em dois anos nós temos eleições e de quatro em quatro anos nós temos Copa do Mundo. Eu não consigo entender como é que, se o Brasil ganhar, vai se favorecer este ou aquele candidato. E as ilações são de toda ordem. Quero dizer que, como brasileiro, eu me orgulho muito de a Copa do Mundo ser aqui no Brasil, fosse em qualquer governo, porque, três dias depois, se o Brasil for campeão ou perder a Copa, nós voltaremos com a página política, e o assunto da Copa do Mundo ficará para o futebol ${ }^{23}$. (...)

A realização da Copa do Mundo não foi somente objeto de embate e foco das falas dos deputados federais, como seu desfecho também serviu de matéria-prima para a construção de discursos associados à disputa política, como é o caso do discurso do deputado federal Izalci (Partido da Social Democracia Brasileira - PSDB, Distrito Federal), no trecho abaixo:

(...) As políticas públicas brasileiras não contribuem em nada para a melhoria do futebol brasileiro ou outros esportes como as Olimpíadas. Por quê? Porque não investimos, não temos organização nas escolas, nas faculdades, nas universidades. Então, o modelo do nosso futebol está falido, assim como o modelo econômico deste governo. É exatamente a mesma coisa. Nós não temos hoje, no Brasil, um trabalho de planejamento. O futebol brasileiro, a seleção brasileira reúne-se quarenta dias antes da Copa, joga tudo ali, e fazem uma propaganda danada. É mais uma ação muito parecida com a do governo. Na televisão, na propaganda, o Brasil já era campeão antes de começar o torneio. O próprio Parreira disse que o Brasil já era campeão antes de começar! Ele garantia isso! É mais ou menos o que acontece com o governo. Na televisão está tudo maravilhoso, mas na prática, 7 a 1 para a Alemanha ${ }^{24}$. (...)

A principal contribuição do expressed agenda model em comparação com as demais metodologias utilizadas na classificação de conteúdo de forma não supervisionada é sua estrutura hierárquica que permite identificar a ênfase de temática de autores. Por tal razão, como última 
estratégia de validação dos resultados obtidos pelo modelo para as legislaturas analisadas, foi averiguada a ênfase temática dos discursos proferidos no Pequeno Expediente pelo deputado federal Romário (Partido Socialista Brasileiro - PSB, Rio de Janeiro), na 54ª legislatura.

O deputado federal Romário é conhecido em todo o país em função de sua atuação como jogador de futebol e, principalmente, por ser um dos grandes jogadores na Copa do Mundo FIFA de 1994, quando a seleção brasileira ganhou o seu tetracampeonato sobre a seleção italiana. Sua fama e reconhecimento são atributos que contribuíram nitidamente para seu desempenho eleitoral no estado do Rio de Janeiro nas eleições de 2010. Eleito, teve seu primeiro mandato como parlamentar durante a $54^{\mathrm{a}}$ legislatura, concorrendo posteriormente de forma vitoriosa ao Senado Federal.

Figura 6

Ênfase temática dos Pronunciamentos realizados pelo deputado federal Romário (PSB-RJ), na legislatura 54

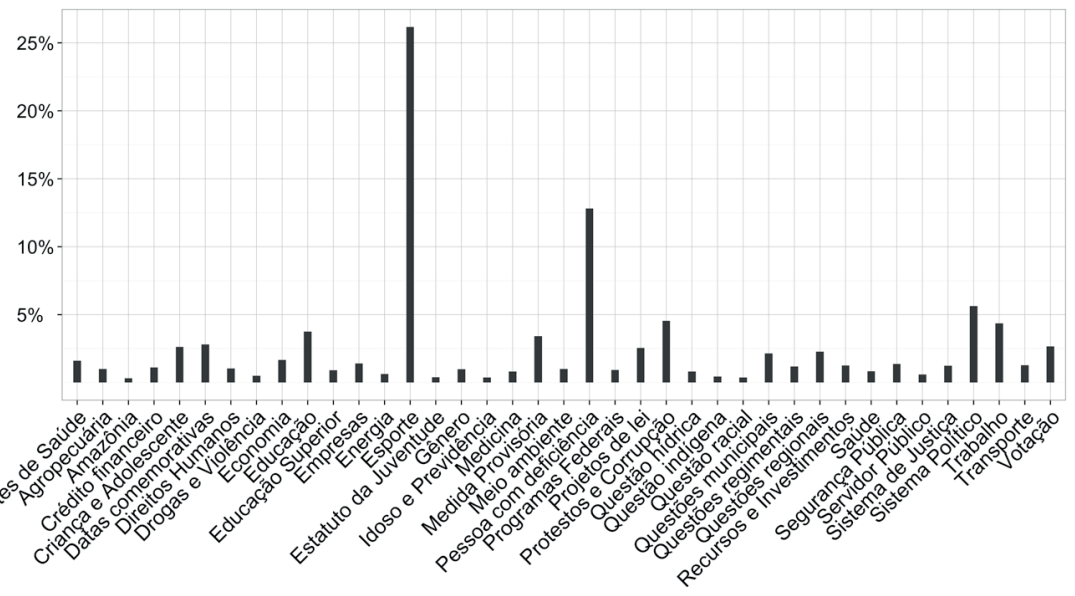

Fonte: elaboração própria com dados da Câmara do Deputados.

Durante seu mandato enquanto deputado federal, o ex-jogador Romário elegeu dois grandes temas para sua atuação: o esporte e as pessoas com deficiência. Como se pode constatar, as falas proferidas pelo deputado federal Romário (PSB-RJ) possuem nítida relação com a sua atuação legislativa. Em discurso realizado em 12 de dezembro de 2012, o parlamentar mostrou-se preocupado com o noticiário a respeito da organização para a Copa das Confederações e para a Copa do Mundo de 2014: 
Boa tarde, senhor presidente, todos os presentes na Casa, senhoras e senhores deputados. Vésperas da realização da Copa das Confederações, que antecede a Copa do Mundo de 2014, o nosso futebol tem ocupado o noticiário nacional e até internacional. Mas, infelizmente, não pelos motivos que gostaríamos. E o problema maior nem é o desempenho da nossa seleção, que, apesar de contar com bons jogadores e até alguns craques, não teve um desempenho satisfatório sob o comando do técnico que antecedeu o atual, o Felipão. O problema maior, o mais preocupante, são as denúncias de irregularidades na exploração e administração do futebol brasileiro pela CBF. A Folha de S. Paulo noticiou, recentemente, que empresas de um amigo de Ricardo Teixeira, ex-presidente da CBF, teriam sido beneficiadas em um contrato de patrocínio da entidade com a companhia aérea $\operatorname{TAM}^{25}$.(..)

Os resultados aqui apresentados são o princípio de uma profícua agenda de pesquisa no campo dos estudos legislativos no Brasil. O expressed agenda model aplicado aos discursos realizados ao longo de mais de 15 anos de atividade parlamentar suscita inúmeras questões diretamente atreladas a seu conteúdo e seu possível desdobramento sobre a dinâmica política nacional.

Longe de ser um fim em si mesmo, o mapeamento de tamanho volume de pronunciamentos pode ser agora utilizado como suporte para pesquisas que não tenham como objeto principal a análise substantiva dos pronunciamentos proferidos. Novas pesquisas podem se valer dos resultados aqui apresentados para tratar de outras dimensões da atividade legislativa ainda pouco exploradas pela $\mathrm{Ci}$ ência Política nacional.

Avançando numa das inúmeras possibilidades de análise que esses resultados permitem, na próxima seção são analisados os padrões de ênfase temática da fala dos deputados federais. Seu objetivo é identificar como se distinguem os parlamentares brasileiros em relação às diferentes agendas políticas proferidas em plenário uma vez que se encontram fora dos constrangimentos institucionais do processo decisório e no momento em que não estão necessariamente submetidos ao domínio de agenda promovido pelo Poder Executivo. 


\section{PADRÕES DE ÊNFASE TEMÁTICA DOS DEPUTADOS FEDERAIS}

Com o objetivo de elucidar padrões gerais desta atividade parlamentar ainda pouco explorada na Ciência Política nacional, especialmente através do uso e aplicação da análise automatizada de conteúdo, optou-se por investigar como os deputados federais se diferenciam diante de duas áreas bastante recorrentes no debate político: a agenda social versus a agenda econômica.

Com base na classificação apresentada nas Tabelas 4, 5, 6 e 7, utilizada para indicar temas próprios do debate econômico e temas peculiares em relação a questões sociais, foi possível calcular três medidas a respeito da ênfase temática de cada parlamentar.

Primeiro, somando-se a ênfase dedicada a cada um dos tópicos referentes à área econômica, foi obtida a ênfase (Ênf.Economia ${ }_{\text {Deputadoi }}$ ) de cada orador nessa área. Segundo, do mesmo modo, obteve-se a ênfase de cada orador sobre a área social (Ênf.Social ${ }_{\text {Deputadoi }}$ ). Por fim, com base nessas duas medidas, calculou-se o balanço (Balanço ${ }_{\text {Deputado }}$ ) entre elas, conforme a equação abaixo apresenta ${ }^{26}$.

$$
\text { Balanço }_{\text {Deputadoi }}=\text { Enf.Social }_{\text {Deputadoi }}-\text { Ênf.Economia }_{\text {Deputadoi }}
$$

Tal medida permite averiguar como os parlamentares brasileiros se diferenciam diante de duas áreas bastante recorrentes no debate político: a agenda social e a agenda econômica. Quanto maior o valor da variável Balanço, maior é a dedicação relativa de um Deputado $i$ a temas da área social. Por contrário, quanto menor o valor da variável Balanço, maior é a dedicação relativa de um Deputado $i$ a temas da área econômica.

Com o objetivo de prover uma análise geral da atividade parlamentar ao discursar no Pequeno Expediente, a Figura 7 apresenta a distribuição dessa variável para todos os oradores que realizaram mais de um discurso no Pequeno Expediente em cada uma das legislaturas analisadas. 
Figura 7

Distribuição da variável Balanço em cada legislatura

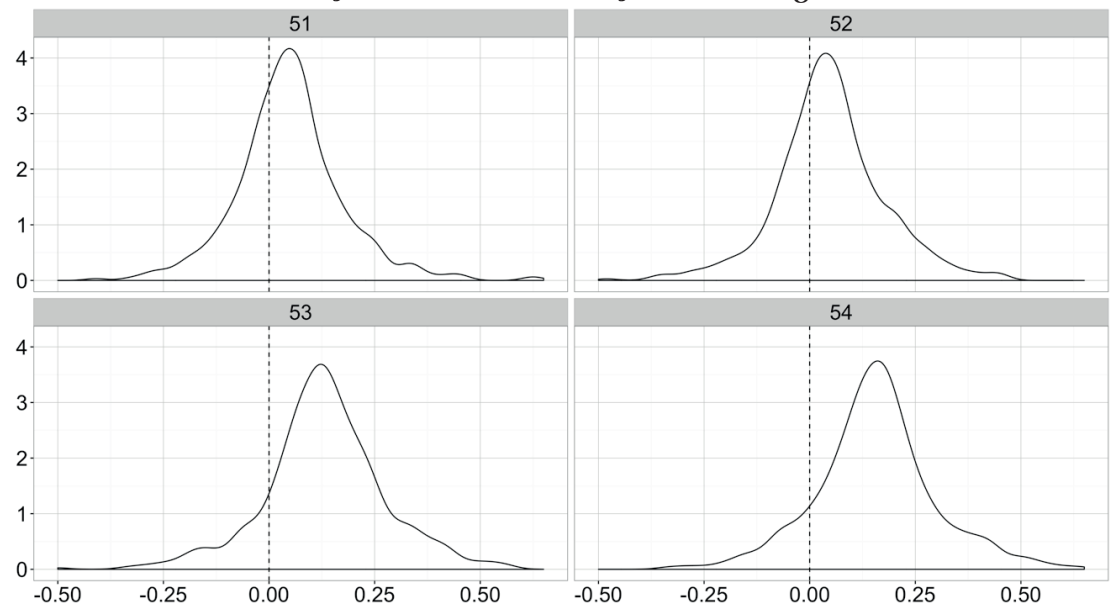

Fonte: elaboração própria com dados da Câmara do Deputados.

De forma geral, a Figura 7 apresenta que é maior a dedicação dos parlamentares brasileiros sobre questões da área social do que sobre questões da área econômica ao discursar no Pequeno Expediente. Assim, adotou-se a variável Balanço como variável dependente para estimação de um modelo multinível linear bayesiano e a investigação da orientação das variáveis preditoras sobre o comportamento observado. O primeiro nível se refere aos parlamentares, sendo esses pertencentes a suas respectivas legendas partidárias $j, j \in\{1, \ldots\}$,$\} , e UFs$ $k, k \in\{1, \ldots, K\}$. Variando o intercepto em função da legenda partidária e da Unidade de Federação (UF) de cada potencial orador, ao modelo estão incluídos preditores individuais para os deputados federais, preditores para as legendas partidárias e preditores que destacam as características de cada UF, conforme exposto na Tabela $8^{27}$. 
Tabela 8

Variáveis preditoras

\begin{tabular}{lc}
\hline & Deputados Federais \\
\hline $\begin{array}{l}\text { \# Discursos } \\
\text { Mulher } \\
\text { \% Votos } \\
\text { \# Legislatura }\end{array}$ & $\begin{array}{c}\text { Quantidade de discursos realizados pelo parlamentar no Pequeno } \\
\text { Expediente. }\end{array}$ \\
\hline & $\begin{array}{c}\text { Variável indicando se o parlamentar é do sexo feminino. } \\
\text { Percentual de votos recebidos na UF }\end{array}$ \\
\hline Esquerda & $\begin{array}{c}\text { Variável indicando se a legenda partidária pela qual o parlamentar } \\
\text { foi eleito é classificada ideologicamente de esquerda ou centro/ } \\
\text { direita. }\end{array}$ \\
Coalizão & $\begin{array}{c}\text { Variável indicando se a legenda partidária pela qual o parlamentar } \\
\text { foi eleito compôs a coalizão governista ao longo da legislatura. }\end{array}$ \\
\hline & Unidades Federativas \\
\hline PIB per capita & Pib per capita da UF no ano de 2010. \\
\hline
\end{tabular}

Fonte: elaboração própria com dados próprios, da Câmara do Deputados, IBGE e NECI-CEBRAP.

A escolha para a modelagem multinível está baseada na estrutura hierárquica do processo de seleção dos possíveis oradores do Pequeno Expediente. Antes de se tornarem deputados federais, todos os possíveis oradores foram candidatos filiados a legendas partidárias em suas respectivas UFs e estiveram submetidos ao escrutínio público de cada localidade. Ademais, mesmo não sendo o caso explícito do Pequeno Expediente, as regras que orientam os trabalhos na CD também consideram essas variáveis no regramento da atuação parlamentar. Desse modo, somada às atuais conclusões sobre o comportamento parlamentar na CD, é importante conceber que além de variáveis pessoais, variáveis vinculadas à legenda partidária e à realidade de cada UF podem ter interferência sobre o tema de cada fala.

A Figura 8 apresenta os principais resultados obtidos na estimação do modelo. O log da quantidade de discursos, a quantidade de legislaturas que o deputado federal compôs e a participação da legenda pela qual foi eleito na coalizão governista não possui qualquer influência sobre a variável Balanço nas legislaturas analisadas. Contudo, verifica-se nas legislatuas 53 e 54 o efeito negativo do log do percentual de votos recebidos na eleição que conduziu o parlamentar ao cargo, indicando provável associação entre esta variável e a ênfase 
temática sobre tópicos da área econômica. De modo semelhante, porém com efeito positivo sobre a variável Balanço, identifica-se que ter sido eleito por uma legenda de esquerda teve correlação positiva sobre a ênfase temática de questões da área social nas legislaturas 52 e 53. Por fim, é notável o efeito positivo do gênero feminino sobre a dedicação a temas da área social em todas as legislaturas analisadas.

Figura 8

Intervalos de Credibilidade estimados para cada legislatura - Balanço

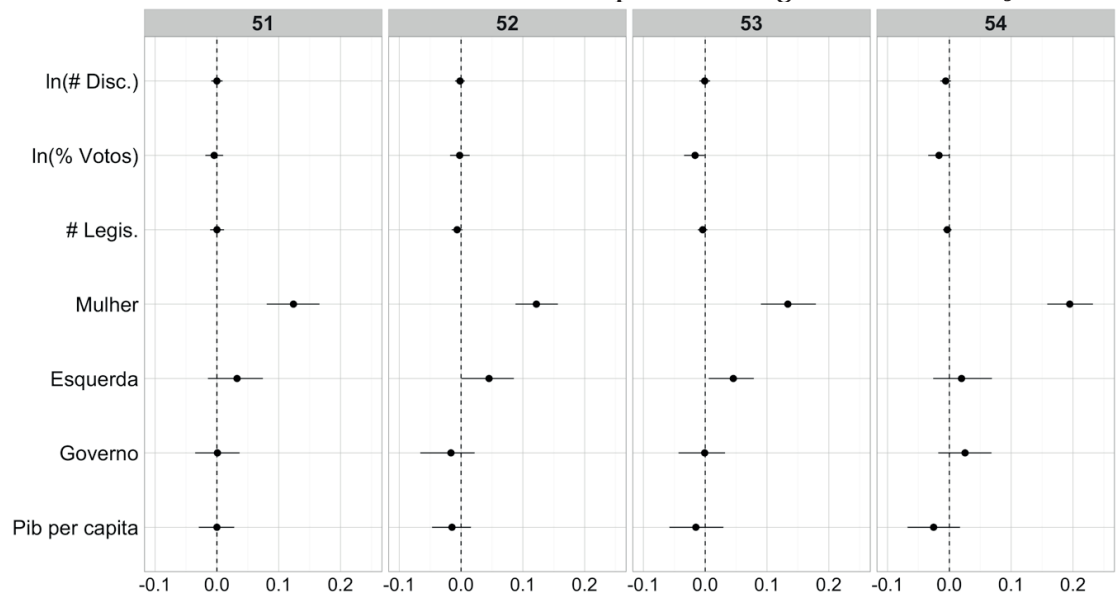

Fonte: elaboração própria com dados da Câmara do Deputados.

Pela Figura 8, verifica-se, portanto, evidências de que a abordagem de temas referentes à área econômica ou à área social está correlacionada ao percentual de votos recebidos, à ideologia da legenda partidária pela qual o parlamentar foi eleito e, especialmente, seu gênero. Corroborando os resultados encontrados por Miguel e Feitosa (2009), em todas as legislaturas deputadas federais apresentaram maior associação a temas da área social do que da área econômica.

Diante da literatura que trata do comportamento geral da atividade parlamentar no âmbito da Câmara dos Deputados, não há qualquer evidência de que a relação governo-oposição oriente o posicionamento temático do deputado federal brasileiro diante de temas próprios da atividade econômica ou temas próprios da área social. Há, portanto, indícios suficientes para defender que a atividade parlamentar no âmbito da Câmara dos Deputados não se reduz à relação governo-oposição e muito menos ao processo decisório. 
Há, na atividade parlamentar, muito mais do que a tarefa de produzir e aprovar leis.

\section{CONSIDERAÇÕES FINAIS}

Com o uso da aprendizagem computacional não supervisionada, por meio do expressed agenda model este artigo superou custos historicamente presentes no trabalho de identificação de conteúdo expresso num imenso volume de discursos políticos. Acompanhando avanço metodológico recente (Grimmer \& Stewart, 2013; Monroe \& Schrodt, 2008; Roberts, 2016), este artigo reconhece o discurso como um dos meios pelos quais a política se materializa e se dedicou à análise de mais de 127 mil pronunciamentos realizados por mais de 2 mil oradores diferentes ao longo de mais de quinze anos de atividade parlamentar.

O artigo foi orientado pela seguinte questão: as agendas proferidas pelos parlamentares em discursos no plenário da Câmara dos Deputados são governadas pela relação governo-oposição, assim como constatado sobre sua atuação no processo decisório?

Através da apresentação de evidências robustas sobre a ênfase temática dos deputados federais que realizaram discursos no Pequeno Expediente e sua dedicação às agendas econômica e social, a resposta é: não.

Amparados pelas regras que organizam os trabalhos na $C D$, porém distantes dos regulamentos que regem os processos decisórios, demonstrou-se que a atividade parlamentar no âmbito da $C D$ vai além da votação e da apresentação de projetos de lei. Os deputados federais possuem tempo, espaço, recursos e infraestrutura dedicados à comunicação política que não se restringem aos projetos em pauta.

Para além da frequência da atividade de comunicação parlamentar, foi apresentada a plausibilidade de uso de métodos de classificação automatizada de conteúdo para acessar os temas enfatizados pelos deputados federais em suas falas. Longe de ser um fim em si mesmo, o mapeamento substantivo dos temas tratados nos pronunciamentos políticos pode ser agora utilizado como suporte para inúmeras questões de pesquisa. 
Com o objetivo de elucidar padrões gerais dessa atividade parlamentar ainda pouco explorada na Ciência Política nacional, verificou-se a propensão temática de cada deputado federal em tratar de duas áreas bastante recorrentes no debate político: a agenda social e a agenda econômica. A ênfase temática dos deputados federais a respeito de questões sociais ou temas próprios da área econômica é distinta, e sua análise evidenciou que tal diferença relativa sofre a influência do percentual de votos recebidos, da ideologia da legenda partidária pela qual o parlamentar foi eleito e, especialmente, de seu gênero, sem qualquer evidência a respeito de seu posicionamento diante a coalizão governista.

Tais resultados destacam que a atividade parlamentar no âmbito da $\mathrm{CD}$ não se reduz à relação governo-oposição e muito menos ao processo decisório. Ademais, esta breve exploração dos mais de 127 mil discursos proferidos no Pequeno Expediente ao longo de mais de 15 anos de atividade parlamentar é apenas o início de uma longa jornada para uma compreensão mais fidedigna da atividade política do deputado federal brasileiro. É necessário, portanto, refinar a tese de que a atividade parlamentar no âmbito da $\mathrm{CD}$ se resume ao posicionamento de sua legenda partidária diante do Poder Executivo.

(Recebido para publicação em 19 de julho de 2018)

(Reapresentado em 5 de fevereiro de 2019)

(Aprovado para publicação em 12 de fevereiro de 2019)

\section{NOTAS}

1. Somadas as legislaturas 51,52, 53 e 54, foram realizadas 1.927 votações nominais na CD. Nesse mesmo período, somente no Pequeno Expediente, foram realizados mais de 127 mil pronunciamentos.

2. A única referência que se destaca nesse quadro de escassez é o trabalho de Miguel e Feitosa (2009).

3. Para mais detalhes, ver Moreira (2016).

4. Importante destacar que há previsão de espera de trinta minutos para preenchimento do quórum mínimo de abertura da sessão. Esse tempo deverá ser deduzido do período destinado ao expediente (art. $79, \S 3^{\circ}$, RICD).

5. A matéria do expediente consiste nas comunicações enviadas à Mesa pelos deputados federais, na correspondência em geral, nas petições e outros documentos recebidos pelo presidente ou pela Mesa, de interesse do Plenário.

6. Para uma análise apurada sobre a frequência de uso dos momentos regimentais de fala na Câmara dos Deputados, ver Moreira (2019). 


\section{Davi Moreira}

7. Cada pessoa foi contabilizada mais de uma vez conforme o número de legislaturas da qual tenha participado. Essa escolha foi feita pois, em cada legislatura, um cidadão eleito deputado federal, torna-se um orador em potencial.

8. Como uma mesma pessoa pode ter sido eleita mais de uma vez ao longo das legislaturas 51 a 54, os 2.262 oradores do Pequeno Expediente representam 1.333 pessoas distintas.

9. Como vimos, considerando os possíveis oradores em cada legislatura, 317 deles (12,3\% de 2.578) não realizaram qualquer discurso no Pequeno Expediente.

10. Para mais detalhes ver Grimmer (2010).

11. Nesse artigo as palavras tópico e tema são usadas como sinônimos.

12. http://www.camara.leg.br

13. Para este artigo, fora desenvolvido em linguagem $\mathrm{R}$ um programa capaz de obter e organizar os dados de forma eficaz.

14. Ver http:/ / snowball.tartarus.org/ e http://www.nilc.icmc.usp.br/nilc/index.php

15. Todo o procedimento de limpeza e organização dos dados foi possível através do pacote $\mathrm{tm}$ do $\mathrm{R}$ e do desenvolvimento de funções próprias.

16. Além desse procedimento, neste artigo foram retiradas palavras selecionadas após análise de uma amostra aleatória de discursos.

17. Estatisticamente, tópicos são funções densidade de probabilidade de palavras (stems, no caso deste trabalho), que determinam a probabilidade de uma palavra ser usada em um discurso sobre um tema (Grimmer, Westwood e Messing, 2014:42).

18. Foram estimados em torno de 36 tópicos para a legislatura 54, 34 para a legislatura 53, 35 para a legislatura 52 e 31 para a legislatura 51.

19. O processo de definição da quantidade de tópicos presentes num corpus e o processo de validação dos resultados são, sem dúvida, demorados e custosos para o analista, pois exigem rigor e tempo consideráveis. Contudo, diante de tamanho volume de documentos e através da definição de uma estratégia clara de abordagem, como está definido nesse artigo, os benefícios obtidos superam os custos do trabalho empreendido.

20. A Informação Mútua entre um tópico e um stem mede a quantidade de informação que o stem provê sobre a possibilidade de um tópico gerar um documento aleatoriamente selecionado no corpus.

21. Essa classificação também foi realizada com a leitura de discursos aleatoriamente selecionados de cada tópico. Através de avaliação qualitativa se fez a classificação.

22. Discurso presente na página da Câmara dos Deputados (www.camara.leg.br), sem revisão do orador.

23. Discurso presente na página da Câmara dos Deputados (www.camara.leg.br), sem revisão do orador.

24. Discurso presente na página da Câmara dos Deputados (www.camara.leg.br), sem revisão do orador. 
25. Discurso presente na página da Câmara dos Deputados (www.camara.leg.br), sem revisão do orador.

26. Grimmer (2013) faz abordagem semelhante ao verificar, no caso americano, quanto cada senador se dedica ao credit claiming ou ao position taking nos press releases que publicou.

27. Diversos trabalhos se dedicaram a classificar parlamentares e legendas partidárias sobre o espectro ideológico (Leoni, 2002; Power e Zucco, 2009; Tarouco e Madeira, 2013; Zucco, 2009; Zucco Jr. e Lauderdale, 2011). Nesse trabalho, com base nas pesquisas de Zucco (2009) e Power e Zucco (2009), optou-se por identificar apenas os partidos de esquerda, são eles: PCdoB, PDT, Partido Popular Socialista - PPS, Partido Socialista e Liberdade - PSOL e Partido dos Trabalhadores - PT. Assim, nesse artigo a variável ideologia assume os valores "Esquerda" e "Centro/Direita". 


\section{Davi Moreira}

\section{REFERÊNCIAS}

ABRANCHES, Sérgio H. (1988), "Presidencialismo de coalizão: o dilema institucional brasileiro." DADOS - Revista de Ciências Sociais, v. 31, n. 1, pp. 5-34.

ARISTÓTELES. (2012), Retórica. Trad.: Edson Bini. São Paulo: Martins Fontes.

ARRETCHE, Marta. (2007), "The veto power of sub-national governments in Brazil: political institutions and parliamentary behaviour in the post-1988 period". Brazilian Political Science Review (Online), v. 2 (se). Disponível em: http://socialsciences.scielo. org/scielo.php?script=sci_arttext\&pid=S1981-38212007000200002\&lng=en\&tlng=en . Acesso em: 15/06/2019.

BLEI, David M. (2012), "Probabilistic topic models". Commun. ACM, v. 55, n. 4, pp. 77-84.

BLEI, David M.; LAFFERTY, John D. (2006), Dynamic topic models. Proceedings of the 23rd International Conference on Machine Learning, pp. 113-120.

FIGUEIREDO, Argelina Cheibub; LIMONGI, Fernando. (2002), “Electoral incentives, parties, and budget policy". DADOS - Revista de Ciências Sociais, v. 45, n. 2, pp. 303-344.

. (1999), Executivo e Legislativo na Nova Ordem Constitucional. Rio de Janeiro: Fundação Getúlio Vargas.

FOUCAULT, Michel. (1996), A ordem do discurso - Aula inaugural no Collège de France, pronunciada em 2 de dezembro de 1970. Trad.: Laura Fraga de Almeida Sampaio. São Paulo: Edições Loyola.

FREITAS, Andréa Marcondes de. (2013), O presidencialismo da coalizão. Tese (Doutorado em Ciência Política). Universidade de São Paulo, São Paulo.

FREITAS, Rafael. (2010), Poder de agenda e participação legislativa no presidencialismo de coalizão brasileiro. Dissertação (Mestrado em Ciência Política). Universidade de São Paulo, São Paulo.

GELMAN, Andrew. (2003), "A bayesian formulation of exploratory data analysis and goodness-of-fit testing*". International Statistical Review, v. 71, n. 2, pp. 369-382.

. (2004), "Exploratory data analysis for complex models". Journal of Computational and Graphical Statistics, v. 13, n. 4, pp. 755-779.

. (2007), "Rich state, poor state, red state, blue state: what's the matter with Connecticut?". Quarterly Journal of Political Science, v. 2, n. 4, pp. 345-367.

. (2011), "Causality and Statistical Learning" American Journal of Sociology, v. 117, n. 3, pp. 955-966.

GRIMMER, Justin. (2010), “A bayesian hierarchical topic model for political texts: measuring expressed agendas in senate press releases". Political Analysis, v. 18, n. 1, pp. 1-35.

(2013), Representational Style in Congress: what legislators say and why it matters. Cambridge: CUP. 
(2015), "We Are All Social Scientists Now: How Big Data, Machine Learning, and Causal Inference Work Together". PS: Political Science E Politics, v. 48, n. 1, pp. 80-83.

; STEWART, Brandon M. (2013), "Text as data: the promise and pitfalls of automatic content analysis methods for political texts." Political Analysis, v. 21, n. 3, pp. 267-297.

; WESTWOOD, Sean J.; MESSING, Solomon. (2014), The impression of influence: legislator communication, representation and democratic accountability. Princeton: PUP.

LEONI, Eduardo. (2002), "Ideologia, democracia e comportamento parlamentar: a câmara dos deputados (1991-1998)". DADOS - Revista de Ciências Sociais, v. 45, n. 3, pp. 361-386.

LIMONGI, Fernando; FIGUEIREDO, Argelina. (1998), "Institutional foundations of coalition presidentialism". Lua Nova, v. 44, pp. 81-106.

(2005), "The budget process and legislative behavior: individual amendments, support for the executive branch, and government programs". DADOS - Revista de Ciências Sociais, v. 48, n. 4, pp. 737-776.

MANIN, Bernard. (1997), The principles of representative government. Cambridge: CUP.

MIGUEL, Luis Felipe; FEITOSA, Fernanda. (2009), “O gênero do discurso parlamentar: mulheres e homens na tribuna da câmara dos deputados". DADOS - Revista de Ciências Sociais, v. 52, n. 1, pp. 201-221.

MONROE, Burt L. (2013), "The five v's of big data political science introduction to the virtual issue on big data in political science political analysis". Political Analysis, v. 5, n. 21, pp. 1-9.

; SCHRODT, Philip A. (2008), "Introduction to the special issue: the statistical analysis of political text". Political Analysis, v. 16, n. 4, pp. 351-355.

MOREIRA, D. Karaokê da Câmara dos Deputados: o uso do microfone na atividade parlamentar - Opinião Pública v. 25, n. 3. Disponível em: <https:/ / www.cesop.unicamp. br/por/opiniao_publica/artigo/635>. Acesso em: 19/12/2019.

. (2011), Benefícios tributários federais e conexão eleitoral: a concessão de benefícios referentes ao PIS, à Cofins e à CSLL. Dissertação (Mestrado em Ciência Política). Universidade de São Paulo, São Paulo.

PEREIRA, Carlos; MUELLER, Bernardo. (2000), "A theory of executive preponderance: the committee system in the brazilian congress". Revista Brasileira de Ciências Sociais, v. 15, n. 43 , pp. $45-67$.

. (2002), "Strategic behavior in a coalition-based presidential system: executive-legislative relations in the budgetary process in Brazil". DADOS - Revista de Ciências Sociais, v. 45, n. 2, pp. 265-301.

. (2003), "Weak parties in the electoral arena, strong parties in the legislative arena: the electoral connection in Brazil".DADOS - Revista de Ciências Sociais, v. 46, n. 4, pp. 735-771.

PORTER, Martin F. (1980), "An Algorithm for Suffix Stripping”. Program: Electronic Library and Information Systems, v. 14, n. 3, pp. 130-137. 


\section{Davi Moreira}

POWER, Timothy J.; ZUCCO, Cesar. (2009), “Estimating ideology of Brazilian legislative parties, 1990-2005: a research communication". Latin American Research Review, v. 44, n. 1 , pp. 218-246.

RICCI, Paolo. (2003), “The content of Brazilian legislative output: national laws or pork barrel politics?". In: Dados, v. 46, n. 4, pp. 699-734.

. (2006), De Onde vêm nossas Leis? Origem e Conteúdo da Legislação em Perspectiva Comparada. Tese (Doutorado em Ciência Política). Universidade de São Paulo, São Paulo.

ROBERTS, Margaret. (2016), "Introduction to the virtual issue: recent innovations in text analysis for social science". Political Analysis, n. 24, v. 10, pp. 1-5.

TAROUCO, Gabriela da Silva; MADEIRA, Rafael Machado. (2013), “Partidos, programas e o debate sobre esquerda e direita no Brasil". Revista de Sociologia e Política, v. 21, n. 45, pp. 149-165.

ZUCCO JR., Cesar. (2009), “Ideology or what? legislative behavior in multiparty presidential settings". The Journal of Politics, v. 71, n. 3, pp. 1076-1092.

; LAUDERDALE, Benjamin E. (2011), “Distinguishing between influences on Brazilian legislative behavior". Legislative Studies Quarterly, v. 36, n. 3, pp. 363-396. 


\section{RESUMO}

Com a Palaura os Nobres Deputados: Enfase Temática dos Discursos dos Parlamentares Brasileiros

Reconhecendo o discurso como um dos meios pelos quais a política se materializa, este artigo tem o objetivo de responder a seguinte questão: as agendas proferidas pelos parlamentares em discursos no plenário da Câmara dos Deputados são governadas pela relação governo-oposição, assim como constatado sobre sua atuação no processo decisório? Para respondê-la, foi feito uso do expressed agenda model para análise do conteúdo de mais de 127 mil pronunciamentos realizados por mais de 2 mil oradores diferentes ao longo de mais de 15 anos de atividade parlamentar na Câmara dos Deputados (1999-2014). Identificada a ênfase atribuída por cada legislador às agendas econômica e social, a resposta é que não. As conclusões apresentadas aprimoram o conhecimento a respeito do comportamento parlamentar no âmbito da Câmara dos Deputados e indicam a influência de outras variáveis sobre sua atuação como, por exemplo: a ideologia, o gênero e a sua popularidade.

Palavras-chaves: discurso; Câmara dos Deputados; análise automatizada de conteúdo; modelagem de tópicos; estudos legislativos

\section{ABSTRACT \\ The Noble Deputies Speak: Thematic Emphasis of the Brazilian Parliamentarians' Speeches}

Recognizing the speech as one of the means through which politics materializes, this article aims to answer the following question: the agendas stated by parliamentarians in speeches in the plenary of the Chamber of Deputies are grounded by the government-opposition relationship, in the same way as observed in the decision-making process? To answer this question, the express agenda model was used in order to analyze the content of more than 127,000 statements made by over 2,000 different speakers during more than 15 years of parliamentary activity in the Chamber of Deputies (1999-2014). Once the emphasis attributed by each legislator to economic and social agendas has been identified, the answer is negative. The conclusions presented enhance the knowledge about parliamentary behavior within the Chamber of Deputies and indicate the influence of other variables on their performance, such as ideology, gender, and popularity.

Keywords: speech; Chamber of Deputies; automated content analysis; modeling of topics; legislative studies 


\section{Davi Moreira}

\section{RÉSUMÉ}

La Parole aux Nobles Députés: Emphase Thématique sur les Discours des Parlementaires Brésiliens

En reconnaissant le discours comme l'un des moyens par lesquels la politique se matérialise, cet article a pour objectif de répondre à la question suivante: les ordres du jour donnés par les parlementaires lors de discours en plénière à la Chambre des Députés sont régis par la relation gouvernement-opposition, telle que vérifiée le dans le processus de prise de décision? Pour répondre à cette question, l' expressed agenda model a été utilisé pour analyser le contenu de plus de 127000 déclarations faites par plus de 2000 orateurs différents au cours de plus de 15 ans d'activité parlementaire à la Chambre des Députés (1999-2014). Depuis que l'importance accordée par chaque législateur aux programmes économiques et sociaux a été identifiée, la réponse est non. Les conclusions présentées améliorent la connaissance du comportement parlementaire au sein de la Chambre des Députés et indiquent l'influence d'autres variables sur leur performance, telles que l'idéologie, le sexe et la popularité.

MOTS-CLÉS: discours; Chambre des Députés; analyse de contenu automatisée; modélisation de sujets; études législatives

\section{RESUMEN}

Con la Palabra los Nobles Diputados: Énfasis Temática de los Discursos de los Parlamentarios Brasileños

Reconociendo el discurso como uno de los medios por los cuales la política se materializa, este artículo tiene por objetivo responder a la siguiente pregunta: ¿las agendas proferidas por los parlamentarios en discursos en el plenario de la Cámara de Diputados son gobernadas por la relación gobierno/oposición, así como es constatado sobre su actuación en el proceso de toma de decisiones? Para responderla, fue usado el expressed agenda model para el análisis de contenido de más de 127 mil pronunciamientos realizados por más de 2 mil oradores diferentes a lo largo de más de 15 años de actividad parlamentaria en la Cámara de Diputados (1999-2014). Identificado el énfasis atribuido por cada legislador a las agendas económica y social, la respuesta es que no. Las conclusiones presentadas mejoran el conocimiento a respecto del comportamiento parlamentario en el ámbito da Cámara de los Diputados e indican la influencia de otras variables sobre su actuación como, por ejemplo: la ideología, el género y su popularidad.

Palabras clave: discurso; Cámara de los Diputados; análisis automatizada de contenido; modelaje de temas; estudios legislativos 